\title{
Malignant Pleural Effusion Management: Keeping the flood gates shut
}

Steven Walker $\mathrm{MBChB}^{1 *}$, Rachel Mercer $\mathrm{MBChB}^{2 *}$, Prof. Nick Maskell D.M. ${ }^{1}$, Prof. Najib M Rahman DPhil ${ }^{3}$

1. Academic Respiratory Unit, University of Bristol, Bristol, UK

2. Oxford Respiratory Trials Unit, Churchill Hospital, Oxford, UK

3. Oxford NIHR Biomedical Research Centre, Oxford, UK

* Dr Walker and Dr Mercer contributed equally to this paper

Corresponding Author: Najib M Rahman Oxford Respiratory Trials Unit, Churchill Hospital, Oxford, OX3 7LE, UK

The authors confirm that this paper has not been submitted to another journal and has not been published in whole or in part elsewhere previously. No medical writers were used to write this review and the review was not funded by any organisations.

Conflicts of interest

RM \& SW declare no conflicts of interest. NM reports grants from BD Medical, grants from Rocket Medical, outside the submitted work and sat on advisory board for BD medical. NMR has received consultancy fees and clinical trials support from Rocket Medical UK, and BD

Contributions

SW and RMM were responsible for initial draft preparation and revision. NM and NMR were responsible for reviewing and approving the final manuscript. All authors are responsible for the overall content as guarantors.

Word Count: 5485

\section{$\underline{\text { Abstract }}$}

With no cure for malignant pleural effusion (MPE), efforts are focused on symptomatic management. Historically, this was achieved with the instillation of a sclerosant agent into the pleural space to achieve pleurodesis. The development of the tunnelled indwelling pleural catheter (IPC) and ambulatory pleural drainage changed the management of MPE, not solely by offering an alternative management pathway, but by challenging how we view success in a palliative condition. Furthermore, with more treatment options available, there is increased imperative to better characterise our patients to enable a personalised approach to their care. We have performed a review of the scientific literature and clinical trial registries to provide an overview of the current and ground-breaking research published in the last 10 years. 


\section{$\underline{\text { Introduction }}$}

MPE is a common and disabling complication of cancer, with a sixth of patients with malignancy developing an effusion during their disease, and an estimated annual incidence of over 150,000 in the USA (1). Until recently, the management pathway was linear, non-personalised and with little supporting research. The British Thoracic Society (BTS) Pleural Disease Guidelines (2), published in 2010, recommended recurrent therapeutic aspirations in patients with MPE and a life expectancy of less than 1 month, but recognised the lack of validated predictors of prognosis. Pleurodesis with a small-bore tube avoiding non-steroidal anti-inflammatory (NSAID) drugs was advocated in all patients who had expandable lung. Indwelling pleural catheter (IPC) use was in its infancy and was only recommended as second line treatment, or in those with non-expandable (trapped) lung. The guidelines were based on the available evidence at the time, but over the past decade the data has increased dramatically, leading to large changes in practice.

Several factors lead to this increased evidence base. Firstly, the recognition that thoracic ultrasound improved the safety of pleural procedures and its subsequent near universal adoption, led to increased interest in the speciality and greater understanding of the underlying disease processes. The introduction of the FDA approved silicon coated IPC offered an alternative approach to managing refractory pleural effusions. The IPC also signalled the arrival of symptom-directed outcomes, where success was measured based on patient-orientated parameters, and not conventional measurement of "success" by an arbitrary, radiological definition of pleurodesis success which was by and large used in older surgical studies(3). This is reflected in more recent pleural clinical trial designs which have moved away from radiographic outcomes to more patient-centred endpoints. Invariably, with more ways of approaching the same problem, there is increased interest how to best phenotype and endotype MPE, with several recently published studies examining scoring systems to evaluate pleurodesis success and prognosis.

This review paper outlines seminal practice changing publications addressing prognostication, inpatient management and outpatient pathways for patients with symptomatic MPE.

\section{Optimising pleural thoracentesis- role of manometry}

The first line approach to a MPE is typically therapeutic aspiration using a cannula or bespoke aspiration kit. This allows assessment of symptom benefit post aspiration, assessment of fluid recurrence and the identification of non-expandable lung on post procedure chest radiograph. The BTS guidelines 2010 suggest a maximum volume of drainage of $1.5 \mathrm{~L}$, as higher drainage volumes were suspected of increasing the risk of re-expansion pulmonary oedema (RPO), and this volume was felt adequate to identify most non-expandable lung and be associated with symptom benefit. Many centres now prefer to perform a large volume aspiration, stopping if the patient develops symptoms of chest pain or cough. The presence of non-expandable lung significantly alters the management pathway, and accurate detection at time of aspiration would expedite definitive management. Unfortunately, there remain no methods of accurately predicting who will develop non-expandable lung or to identify its presence prior to aspiration. Pleural manometry allows a greater appreciation of the pressures changes in the pleural space during aspiration and was felt to be a potential solution for identifying and characterising non expandable lung more accurately.

Lentz et al produced the first randomised study to address the clinical utility of pleural manometry during routine thoracentesis, comparing manometry to symptom guided aspiration in 128 patients(4). The primary outcome was unique, in that it directly addressed a patient centred outcome (chest 
discomfort during pleural aspiration), with secondary outcomes including volume drained, procedure duration, lung re-expansion and post procedure radiograph appearance. The trial found no significant differences in outcomes between groups, apart from a higher rate of ex-vacuo pneumothoraces in the control group $(p=0.012)$. This supported previous observational data that manometry could not predict RPO, and represents the highest quality study to date to directly address the clinical utility of pleural manometry, using patient focussed outcomes; on the basis of this data, there is no clear role for pleural manometry in routine pleural aspiration. It is important, however, to appreciate that determining and interpreting pleural pressure is difficult, and care needs to be taken in establishing whether these results represent a genuine non-difference between symptom and manometry guided thoracentesis, or whether it reflects our inability to accurately assess the changes of pleural pressures. There are plausible physiological reasons why measuring pleural pressures may not decrease risk of chest pain, with previous studies demonstrating an inconsistent relationship between pleural pressures and chest pain(5) and it is possible that pressure thresholds for chest discomfort may vary between patients(4). On the other hand, there are concerns that these measurements truly reflect the pressures in the pleural cavity. The pressures were only taken during brief interruptions in the drainages, and it is plausible that acute changes in pleural pressures were missed during the periods. Furthermore, even with digital manometers, capturing true end-expiratory pressures, which change multiple times during the respiratory cycle, is not easy and may confer inaccurate end-expiratory pressures(6).

Despite Lentz et al finding no benefit in the routine use of pleural manometry in predicting pain and complications during thoracentesis, it still may have value in predicting non-expandable lung and directing the clinician to an appropriate management pathway. A study specifically addressing whether pleural elastance assessment during therapeutic aspiration can successfully triage patients to either IPC or talc pleurodesis management is currently recruiting (7). A change in pleural elastance of $>14.5 \mathrm{~cm} \mathrm{H} 20 / \mathrm{L}$ is used to denote negative pleural pressure and therefore non-expandable lung, which indicates that pleurodesis is less likely to be successful and insertion of an IPC would be recommended. If this can be established whilst enough fluid remains in the chest to allow for tube placement, it would allow for triage to IPC or pleurodesis at the time of initial aspiration and has the potential to alter our current non-directed treatment paradigm.

The main clinical significance of non-expandable lung is related to pleurodesis failure. Manometry may identify a cohort of patients who have a change in pleural elastance suggestive of non-expandable lung but with a subsequent normal chest radiograph. It is plausible that this group could still be a highrisk of pleurodesis failure as the lung recoils away from the chest wall, in small degrees, which may not be evident radiographically. This lack of pleural apposition could be a driver for pleurodesis failure which has, until now, not been identified. This entirely new field may allow for more informed patient choices, but further directed work is needed to fully define the area.

\section{Pleurodesis - challenging the dogma}

Chemical pleurodesis with instillation of a chemical sclerosant via a chest tube at the bedside has been the long-established management of refractory MPE. Perhaps because of this, its practice has been based on long-standing canon in the absence of scientific rigor. The choice of sclerosant was mainly based on where physicians practiced, size of drain was based predominately on personal experience, and NSAIDs were universally avoided due to concerns that their anti-inflammatory action would 
impede pleurodesis. Over the last 10 years, a series of large RCTs and robust meta-analyses has created a clearer picture of the definition of optimal pleurodesis.

The choice of sclerosant available is wide, with no clear consensus and practice based on regional preference. The trial data reflects this, with numerous small studies examining differing agents. A Cochrane review by Clive et al proposed to combine these data, reviewing 62 studies involving 3428 patients to assess the effectiveness of different methods of pleurodesis (8). It concluded that instillation of sterile talc via thoracoscopy (poudrage) was more effective than many of the commonly used methods, although due to high heterogeneity and risk of bias, the analysis could not definitively state its superiority over other methods (such as talc slurry via chest drain). This question of the optimal method of administrating talc, either at thoracoscopy (poudrage) or via chest drain (slurry) has not yet been convincingly answered; however, the TAPPS trial which directly addresses this question has recently completed recruitment and follow up of 330 patients, and this study should provide definitive information (9).

The TIME 1 trial sought to answer two important questions concerning talc pleurodesis by way of a $2 \times 2$ factorial phase 3 randomized clinical trial. The first question addressed optimal chest drain size, comparing small-bore (12Fr) to large-bore (24Fr) drains. Secondly, it addressed for the first time in humans whether NSAID administration impaired pleurodesis, compared to opiate use (10). A total of 320 patients with MPE requiring pleurodesis were enrolled, with co-primary outcomes of pain during admission (superiority comparison) and pleurodesis at 3 months (non-inferiority comparison, with a pre-specified threshold of $15 \%$ ). There was no significant difference in pain scores between the analgesia groups, but the NSAID group received a modestly higher number of rescue doses of analgesia (median 1 per patient). NSAIDs were demonstrated to be non-inferior in terms of pleurodesis success at 3 months. The large-bore $24 \mathrm{~F}$ chest drains were, on average, more painful than the small-bore $12 \mathrm{~F}$ drains ( $26 \mathrm{vs} 22 \mathrm{~mm}$ respectively), although the absolute difference on average in pain scores were small. However, for the pleurodesis outcome, 12/50 (24\%) patients with 24F drains had pleurodesis failure compared to $15 / 50$ (30\%) with $12 \mathrm{~F}$ drains, and $12 \mathrm{~F}$ drains failed to meet the $15 \%$ criteria for non-inferiority. Smaller drains were associated with a higher rate of early fall out, smaller bore patients were at higher risk of not receiving talc and were associated with modestly increased complications at insertion. These results imply that small-bore chest drains are not as effective as large-bore chest drain in achieving pleurodesis, however, the number of patients in the pleurodesis analysis was smaller than intended due to the inclusion of patients undergoing thoracoscopy in this study, and therefore further confirmatory studies are proposed to understand this signal fully. Nonetheless, the study results challenge the current trend of small-bore drain use for all indications.

The current recommended practice for timing of talc instillation and chest tube removal based on the volume of fluid output is based on little evidence. With increasing use thoracic ultrasound (TUS), it has been proposed a superior method might be to examine for satisfactory apposition of the parietal and visceral pleura, and sonographically assess fibrin deposition in the pleural space. The use of TUS to determine pleurodesis success has been shown in animal models of chemical pleurodesis, where a TUS score showing absence of lung sliding (the movement between visceral and parietal pleura) has been associated with the development of a successful pleurodesis(11). A small prospective observational study tested the hypothesis in 20 patients, concluding that pleural adhesion was shown on ultrasound in $13 / 20$ patients after 24 hours, and it may thus be possible to remove drains earlier based on ultrasound findings (12). A currently recruiting randomised controlled trial (RCT) was designed to investigate whether using this ultrasound score would allow a reduction in hospital length of stay (SIMPLE - ISRCTN16441661) and is near the end of recruitment. 
These trials have challenged accepted dogmas and filled knowledge gaps. TIME 1 trial was the first, multicentre randomised trial in malignant pleural disease addressing pleurodesis method. The hypothesis that NSAID analgesia reduces pleurodesis success was disproven and it was demonstrated that smaller chest drains cannot be considered "equivalent" to larger bore drains for pleurodesis. A recent Cochrane review could not determine the most effective method of pleurodesis but did agree that sterile talc was the most effective agent. Lastly advances in practice have allowed the utilisation of thoracic ultrasound in identifying pleural adhesions and may revolutionise the way clinicians conduct pleurodesis care.

\section{The Surgical Option}

Surgical pleurectomy is not currently recommended in the treatment of MPE (2), but some doubt remains as to whether surgery may in fact offer a better option to selected patients with MPE than medical pleurodesis methods. The largest and only randomised study assessing this was performed in patients with mesothelioma. MesoVATS was a randomised study directly comparing surgical treatment, using video assisted partial pleurectomy (VATS-PP), to "physician" talc pleurodesis, either by talc slurry or poudrage (13). The study demonstrated no significant difference in the primary outcome of survival at one year $(52 \%$ [95\% $\mathrm{Cl} 41-62]$ in the VAT-PP group compared with $57 \%$ [Cl 46$66]$ in the talc pleurodesis group, hazard ratio 1.04 [95\% $\mathrm{Cl} 0.76-1.42] ; \mathrm{p}=0.81$ ). There were no significant differences in measures of fluid control, measured in this study by chest radiography alone. Complications and the length of stay, were both higher in the VATS-PP group (median hospital stay VATS-PP group 7 days (IQR 5-11) compared with 3 days $(2-5)(p<0.0001)$ ) and the cost of VATS-PP was higher without any significant improvement in survival or quality of life - a single quality of life measure was in favour of VATS-PP in those that survived 6 months.

This important study demonstrated that surgery has no advantage over medical treatment in mesothelioma in terms of survival, fluid control or quality of life, but higher complications and costs. The methodology for measuring fluid control (chest radiograph only with no information on requirement for further pleural procedures) is not now considered robust, as pleural malignancy is difficult to differentiate from fluid on plain chest radiograph. Although a single quality of life measurement was in favour of VATS-PP, this only occurred at 6 months where there had been significant attrition of patients. Further studies assessing surgery vs indwelling pleural catheters (IPC) will be discussed later in this article.

\section{Indwelling Pleural Catheter-changing the paradigm}

Insertion of an IPC to facilitate long-term drainage of a refractory MPE, has been traditionally recommended in guidelines (2) as a second-line approach, after conventional pleurodesis with a sclerosing agent has failed or for patients with non-expandable lung. However, over the last decade a wealth of robust RCT evidence has been published, demonstrating IPCs as an effective first line method for controlling dyspnoea. These trials have also moved beyond the passive use of the IPC as a simple drainage system, to a more active role, with regimes incorporating aggressive drainage or instillation of sclerosants aimed at inducing rapid pleurodesis. Additionally, during this time the design of pleural clinical trials has matured, moving away from radiographic outcomes to more patientcentred endpoints. The following five clinical trials are the seminal studies which have established 
IPC's position in the management pathway of MPE and expanded its role beyond a simple ambulatory chest drain.

The TIME 2 trial was the first to directly examine whether using an IPC or the instillation of talc slurry via a chest tube was effective at relieving dyspnoea, as assessed with a visual analogue scale (VAS) dyspnoea score (14). Patients with MPE without preceding pleurodesis were randomised to either IPC insertion or chest drain with talc instillation. IPCs were inserted as an outpatient, with subsequent home drainage 3 times weekly or as required for the relief of dyspnoea. The talc group were admitted with chest tube insertion and subsequent talc slurry pleurodesis. Dyspnoea improved in both groups, although there was no significant difference in the mean VAS dyspnoea for the first 42 days comparing the IPC and talc groups (Difference of $0.16 \mathrm{~mm} ; 95 \% \mathrm{Cl},-6.82$ to $7.15 ; \mathrm{p}=0.96)$. IPC insertion was associated with significantly shorter length of hospitalisation (difference -3.5 days; $95 \% \mathrm{Cl},-4.8$ to 1.5 days; $p<0.001$ ) and fewer pleural procedures (odd ratio, $0.21 ; 95 \% \mathrm{Cl}, 0.04-0.86 ; p=0.03$ ). Adverse events were higher in the IPC cohort (odd ratio, 4.70; 95\%, 1.75-12.60; $p=0.002$ ). The adverse events were predominately related to infection (pleural and cellulitis).

The AMPLE study examined whether IPCs were more effective than talc pleurodesis in reducing total hospitalisation in patients with MPE(15). IPCs were inserted as a day case, with subsequent drainages in the community guided by symptoms. The talc group were admitted for chest tube insertion, followed by talc slurry instillation. Of the 146 patients randomised, the total all-cause median hospital stay was shorter in the IPC group (10 days) when compared to talc pleurodesis arm ( 12 days) $(95 \% \mathrm{Cl}$, $0.43-5.84 ; p=.030$ ), with the reduction mainly attributed to a decrease in effusion-related hospitalisation days. Fewer patients randomised to IPC required further ipsilateral pleural procedures when compared to talc cohort ( 4 vs 22 respectively; $p=0.001$ ). Serious adverse rates were $1 \%$ and $4 \%$ in the IPC and talc group respectively. Overall adverse rates were higher in the IPC cohort ( 30 vs $18 \%$ ).

The ASAP trial examined whether aggressive daily drainages of the IPC were superior than the current standard of alternate day drainages in achieving autopleurodesis(16). In the 149 patients randomised, the rate of autopleurodesis, defined as complete or partial response based on symptomatic and radiographic changes, was greater in the aggressive drainage arm than the standard arm ( $47 \%$ vs $24 \%$, respectively; $\mathrm{p}=.003$ ). Additionally, median time to autopleurodesis was shorter in the aggressive arm (54 days; $95 \mathrm{Cl}, 34-83$ ) than the standard arm (90 days; $95 \% \mathrm{Cl} 70$ to non-estimable). Adverse events rate, quality of life and patient satisfaction scores were comparable between the two groups.

The AMPLE-2 trial examined whether aggressive (daily) drainages of IPC compared to drainages when symptomatic were superior in providing breathlessness control(17). In the 87 patients randomised, the was no difference in mean daily breathlessness scores during the $1^{\text {st }} 60$ days (geometric mean, $13.1 \mathrm{~mm} ; 95 \% \mathrm{Cl}, 9.8-117.4$; vs $17.3 \mathrm{~mm} ; 95 \% \mathrm{Cl}, 13.0-22.0 ; \mathrm{p}=.18)$. More patients in the aggressive drainage group achieved spontaneous pleurodesis (37.2\%) than the symptom guided group at 60 days (11.4\%) (HR, 3.287: 95\% Cl, 1.360-7.740; $p=.0065)$. Patient reported quality-of-life measures were better in the aggressive group (estimated difference in mean, $0.112 ; 95 \% \mathrm{Cl}, 0.0198-0.204 ; \mathrm{p}=.0174$ )

IPC-plus examined whether talc administration through an IPC was more effective at inducing pleurodesis than the use of IPC alone(18). Patients with MPE had an IPC inserted, with maximal drainage at catheter placement and then a minimal of 4 further drainages before a chest radiograph at day 10 to rule out substantial lung entrapment. Patients were then randomised to receive either $4 \mathrm{~g}$ of talc slurry or placebo via the IPC as an outpatient, with patients blinded to intervention. In the talc group, 30 of the 69 (43\%) had successful pleurodesis at day 35, compared with 16 of the $70(23 \%)$ in the placebo group (hazard ratio, 2.20; 95\% confidence interval, 2.23 to 3.92; $p=.008$ ). There was no significant increase in IPC blockages rates or adverse events in the talc group. 
The TIME 2 trial and AMPLE study compared IPC directly to talc slurry pleurodesis. The TIME 2 trial showed comparable relief in dyspnoea whereas the AMPLE study demonstrated a statistically significant reduction of total hospitalisation time for patients with a MPE who are managed with an IPC compared to talc slurry pleurodesis. The TIME 2 trial showed a higher adverse event rate in the IPC arm and it is not clear that a reduction from 12 to 10 days total inpatient stay in the AMPLE trial represents a clinically significant difference for the patient. Nevertheless, these finding, combined with fewer ipsilateral pleural procedures in the IPC cohort helped to further define its role in this population. By highlighting the potential benefits of IPCs, such as shorter hospital stay as well as potential draw-backs, such as higher adverse event rates, these studies helped to inform patient choice on the available options.

ASAP, AMPLE-2 and IPC-Plus focussed on achieving pleurodesis with an IPC, either via autopleurodesis or the introduction of a sclerosing agent, to allow the removal of the catheter. The ASAP trial showed a more aggressive drainage regime resulted in higher rates of pleurodesis, although many patients in both arms dropped out or died before the primary end point timeline was reached. There was no evidence of quality of life improvement. The AMPLE-2 trial showed both regimes were equally effective in improving breathlessness, but that aggressive drainage increases autopleurodesis rates and for the first time showed an improvement in quality of life. IPC PLUS demonstrated that talc instillation doubled the chances of pleurodesis, without increased rates of adverse events, supporting its use as part of an ambulatory pathway. Of particular importance was the lack of increased risk of development of a symptomatic loculated effusion after talc instillation.

The permutations in IPC management and their associated outcomes of length hospitalisation and time until pleurodesis have health-care cost implications, in addition to implications on the individual. The reduction of hospital length by from 12 to 10 days in patients managed with IPCs in the AMPLE study may not be important for the individual patient but have financial implications when extrapolated across a health system. Similarly, the reduced median time until pleurodesis with accelerated IPCs regimes has cost-implications. The drainage bottles are expensive and, if there is a high volume of drainage over a long period of time this may negate any cost saving from the avoidance of an inpatient admission. Any cost analysis needs to be clear about the relative costs of inpatient stays compared to the care and equipment in the community in different healthcare systems with different funding models. A cost-analysis of patients in the TIME 2 compared patients managed with IPCs to patients managed with talc pleurodesis, finding no difference in overall mean cost $(\$ 4,993$ versus $\$ 4,581$ respectively, $95 \% \mathrm{Cl}$ of $-\$ 1,387$ to $\$ 2,261)(19)$. The cost associated with IPCs management increased with time, with survival of $<14$ weeks skewing the cost-benefit toward the IPCs pathway. These health economic assessments were primarily derived from the U.K. and Australia and may not be applicable to all healthcare services depending of the relative costs of homecare services, inpatient stays and equipment costs.

Current and future research aims include developing effective strategies of inducing pleurodesis to facilitate IPC removal, both for patient comfort and to reduce the cost and potential complications of long-term drainage. The rate of successful pleurodesis with IPCs is appreciably lower than that of chest drain and talc pleurodesis, even when talc was instilled via an IPC in expandable lung (18). This could be related to the inability to maintain a 'dry' pleural space post pleurodesis, compared to when a chest drain is connected to an underwater seal for patients undergoing an inpatient pleurodesis. This may also reflect the thrice weekly standard drainage regime taken during this trial, rather than more aggressive drainage. The encouraging results achieved by the aggressive daily drainages of ASAP and AMPLE-2 reinforces that keeping the pleural space dry is key to prompting autopleurodesis and further 
studies are required to examine whether combining talc and aggressive drainages would achieve higher pleurodesis rates. A summary of the recent trials is provided in figure 1.

Future work on whether the IPC can be used as more than just a drainage catheter, or conversely research into whether persistent exposure to pleural fluid is associated with poor prognosis, may help crystallise the place of the IPC in the management algorithm of MPE. 


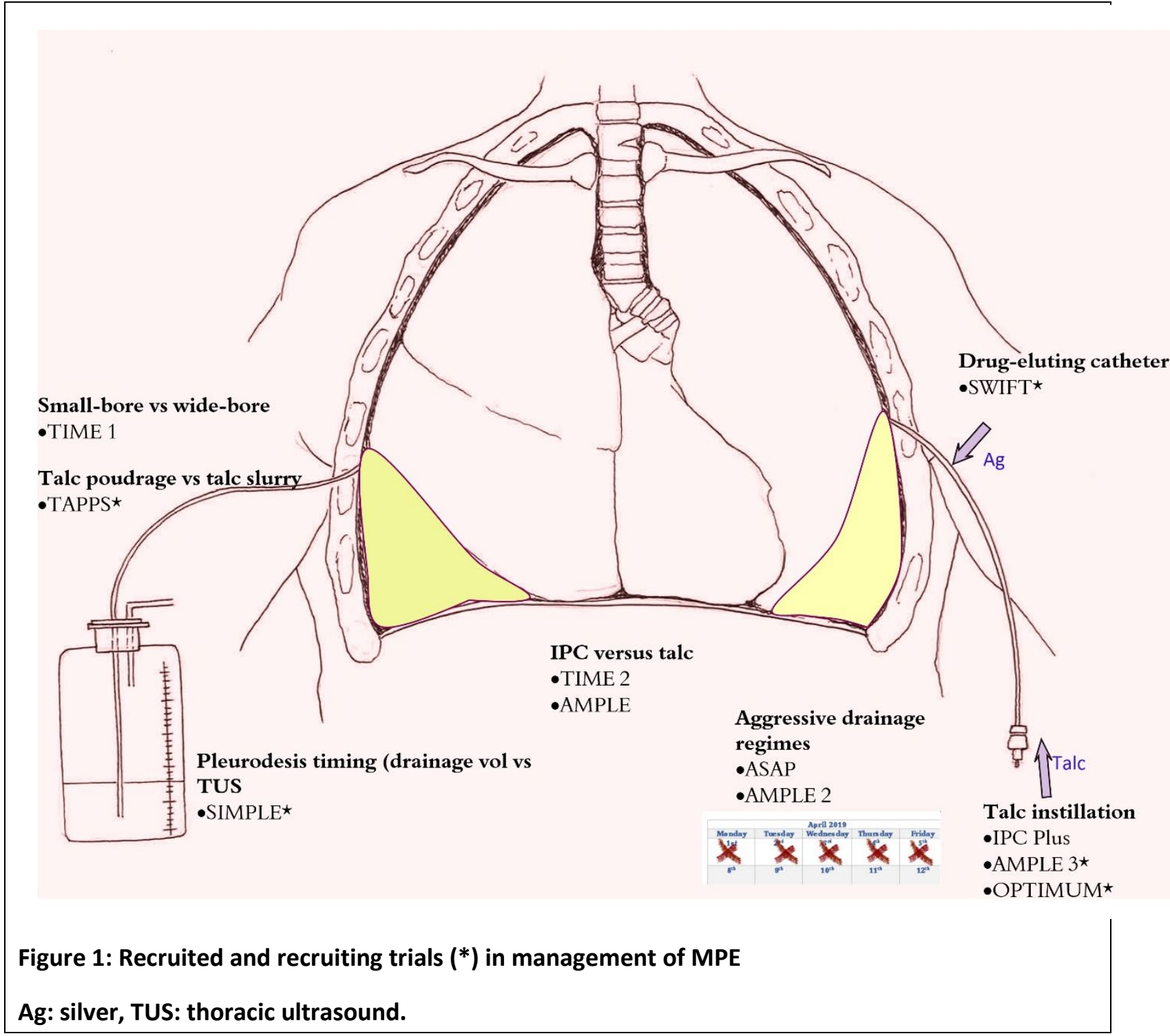

\section{The septated malignant pleural space}

Patients with a septated MPE are notoriously difficult to manage. The BTS guidelines recommended intrapleural fibrinolytics in patients with a non-draining, septated pleural space, although the recommendation was based on radiological rather than patient reported outcomes.

The TIME3 study assessed the effects of intrapleural fibrinolytics (urokinase) on dyspnoea and pleurodesis success in patients with septated MPE using a double blind, placebo-controlled trial(20). Dyspnoea was measured using the $100 \mathrm{~mm}$ VAS scale for breathlessness with an established clinically significant difference of $19 \mathrm{~mm}$. The secondary endpoints were chest radiograph change, survival, length of stay, adverse events and blood parameters. The study demonstrated no significant difference in mean dyspnoea between groups (mean difference $3.8 \mathrm{~mm}, 95 \% \mathrm{Cl}-12$ to $984.4 \mathrm{~mm}$, $p=0.36$ ) or pleurodesis failure (urokinase $13 / 35(37 \%)$, 99 placebo $11 / 34(32 \%)$, adjusted hazard ratio $1.2, p=0.65)$. However, urokinase demonstrated significant improvement in chest radiograph appearance, reduced length of hospital stay and appeared to improve survival. Although this trial did not demonstrate significant improvement in dyspnoea or pleurodesis success, the unexpected very poor survival (median of 2 months) may mean that there was insufficient time for these outcomes to 
change. The change in radiographic appearance suggests biological activity of intrapleural urokinase and there were no significant urokinase related adverse events and importantly, no bleeding related adverse events. This suggests that urokinase should not be used routinely in such patients but may have a role in those with longer potential survival and septated effusions with significant sized collections on chest radiograph.

\section{Personalising MPE management - Prognostication}

With the increasing management options for MPE there is a need for better stratification to enable selection of an optimal management strategy. Prediction of survival in MPE would be of value in triaging patients with good prognosis to a more aggressive pleural and oncological interventions, whereas patients with a poor prognosis would be managed with less invasive procedures aimed at symptom control. Two recent publications have developed and prospectively validated prognostic scores in MPE.

The LENT score was derived using 3 prospectively collected datasets, assessing for factors predictive of survival in patients with MPE (21). Effusion size, Eastern Cooperative Oncology Group performance score (ECOG-PS), pleural fluid lactate dehydrogenase (LDH), serum neutrophil-to-lymphocyte ratio (NLR), serum NT-proBNP and malignant cell type were all independently associated with survival in this model. Four of the most clinically applicable variables were selected (pleural fluid LDH, ECOG PS, NLR and tumour type) to produce the LENT score. This score separated the patients into low, moderate and high-risk groups. Median survival for the cohorts were; low 319 days (228-549; $n=43$ ), moderate 130 days (47-467; $n=129)$ and high risk 44 days $(22-77 ; n=31)$. In the validation cohort, at 3 and 6 months the LENT score was significantly better than ECOG PS alone in predicting survival $(p=0.002$ and $p<0.001)$ but the difference was not significant at 1 month $(p=0.360)$.

The PROMISE study aimed to develop a clinical prognostic score for MPE, but in addition, to discover and validate new biological markers using cutting edge techniques in translational medicine (22). PROMISE used 5 patient cohorts for discovery, validation and prospective assessment $(10,14,20,23)$. Patients were stratified into poor ( $<3$ months) and good survival ( $>3$ months) and pleurodesis success or failure. From 1250 proteins, only 4 proteins finally remained significantly associated with survival and none for pleurodesis success. Regression analysis from the dataset produced 7 variables for the clinical score with the addition of pleural fluid tissue inhibitor of metalloproteinases 1 (TIMP 1) levels for the biological score. The clinical factors were ECOG PS, previous chemotherapy and radiotherapy, cancer type, white blood cell count, c-reactive protein and haemoglobin. Stratifying into 4 categories by PROMISE score demonstrated that the lowest risk group had a less than $25 \%$ risk of death at 3 months, compared to the highest risk group who had a greater than $75 \%$ risk. A nomogram was derived associating individual PROMISE score (from 0 to 43 ) and risk of death at 3 months. This score was externally validated using a separate cohort and produced $C$ statistic values of $0.89(95 \% \mathrm{Cl} 0.84$ $0.93)$ for the clinical score and $0.90(0.84-0.93)$ for the biological score. The PROMISE study has provided a wealth of much needed information on pleural biomarkers, several of which may provide targets for future treatment. However, despite identifying several thousand proteins, only 4 pleural biomarkers (TIMP1, GSN, VCAN, MIF) were identified as predicting risk of death and no biomarkers where useful in predicting pleurodesis success. Of these biomarkers, only the TIMP1 protein formed part of the final scoring system, and this only accounted for a maximum of 2 out of the total possible 43. This lack of success in identifying pleural biomarkers, particularly in determining pleurodesis success demonstrates the challenges in characterising MPEs caused by a heterogenous group of primary malignancies(24). Moving forward, better personalisation should aid biomarker identification. 
The LENT score was the first validated score, showing significant promise in predicting survival in MPE. However, over $60 \%$ of patients fell into the moderate risk group, which also had the widest range of survival, potentially limiting clinical applicability. The PROMISE score predicted mortality more effectively for the individual patient and is the first study to demonstrate a robust pleural fluid protein signal associated with survival. As such, the study provides a greater understanding of some of the pathways implicated in poor outcomes for MPE and may provide future treatment targets. However, the PROMISE score is relatively complex and may not be as applicable in daily practice as LENT. Knowledge of likely prognosis is clearly beneficial to both the patient and treating physician, as it allows better discussions on optimal treatment pathways. It should be noted, however, that neither of these scoring systems have been implemented and shown to improve patient reported outcomes; further studies assessing their impact on the clinical pathway and outcomes such as quality of life are now required. 


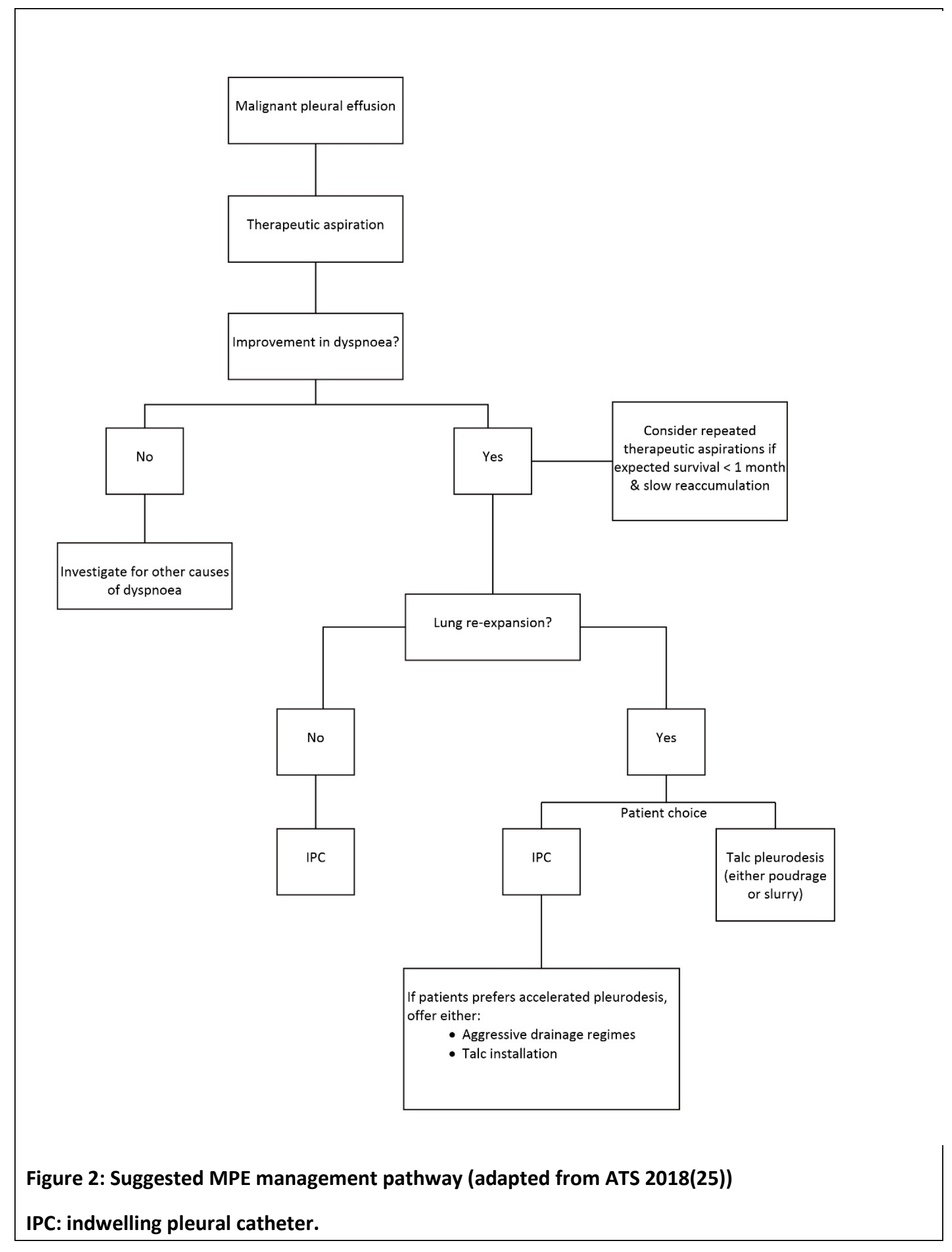




\section{Future direction- controlling the flow}

The last 10 years have challenged our longstanding practices and provided evidence for newer techniques. The findings of these studies are reflected in the recent Official ATS/STS/STR Clinical Practice Guidelines on the Management of Malignant Pleural Effusions (25) which recommends that for patients with suspected expandable lung and no prior definitive therapy, and whose symptoms are attributable to the effusion, either IPCs or chemical pleurodesis be used as first-line definitive intervention for management of dyspnoea. Figure 2 provides an adapted version of this pathway. These recommendations are echoed in the ERS/ EACTS statement on the management of malignant pleural effusions (26) which also highlight the lack of robust evidence for the management of patients with loculated effusions or non-expandable lung.

The next 5 years will further explore accelerated auto-pleurodesis regimes, with two further recruiting studies examining instillation of talc via the IPC (see table 1). There are exciting possibilities with drugeluting catheters, including a silver-nitrate coated IPC (SNCIPC) which slowly elutes the pleurodesis agent over time and a recent pilot clinic study showing safety(27). This device is currently being investigated in a large phase 3 trial (https://clinicaltrials.gov/ NCT02649894). The possibility of using a pleural pump, draining the pleural space directly into the urinary bladder, has also been explored (28).

Important work has explored the experience of patients with pleural malignancy and their carers(29, 30). The first RCT examining the role of early specialist palliative care (SPC) on quality of life for malignant pleural mesothelioma was published recently(31). Whilst it did not demonstrate a difference in health-related quality of life outcomes between early SPC and standard care, it provided interesting insights into their holistic care. Further studies have looked at the role of nutrition, exercise, and complementary medicine in patients with mesothelioma(32). Considering $94 \%$ of these patients complain of fatigue and $87 \%$ appetite loss, future work should broaden its focus to address their entire symptoms burden(33).

The ultimate aim in MPE should be "turning off" pleural fluid formation(34). New translational research, such as the PROMISE study, has identified possible biological markers as therapeutic targets(22). Early work has examined antiangiogenic agents to reduce vascular hyperpermeability and resultant pleural fluid formation(35). Exciting new work is being undertaken, not solely using the IPC as a route to instil oncological therapies intrapleurally, but as a port to serially sample pleural fluid. This may shed light on the understudied tumour microenvironment, which is not a simple reflection of its primary tumour. It is clear the composition of the MPE is influenced by the site of the primary cancer, with differing immune profile of pleural effusions secondary to mesothelioma compared to lung or breast cancer(36). However, the pleural metastases tumour have been demonstrated to be discordant from their primary carcinoma, with substantial difference in epidermal growth factor receptor (EGFR) mutation status between primary tumours and corresponding pleural metastases(37). Clearly, greater understanding is required to facilitate target pleural therapies and intrapleural chemotherapy that have been studied have produce mixed results (38-40). Immunotherapies have provided great strides in the management of cancer, with substantial progress in the understanding in molecular and cellular bases of T-cell-mediated antitumour responses(41) and there has been increasing interest in intrapleural immunotherapies to promote the adaptive immune 
system $(38,42-45)$. As well as increased local effects, it is postulated that this will enable the dissemination of memory T-cells capable on controlling disease systemically(38).

By enabling longitudinal evaluation of tumour and immune cells during immunotherapy and chemotherapy, IPC may facilitate identification of clinically actionable targets present within the tumour and immune cells, allowing for development of effective patient-specific treatments (38). This is a largely unassessed area of research and is likely an important direction for the future.

In 10 years' time, the scope of pleural disease will likely be unrecognisable, and as our understanding of pleural formation increases, the potential for directed intrapleural biological treatments reducing the need for symptomatic drainages.

\begin{tabular}{|c|c|c|c|c|c|c|c|c|}
\hline Intervention & Comparator & Trial design & $\begin{array}{l}\text { Single or } \\
\text { multicentre }\end{array}$ & $\begin{array}{l}\text { Primary outcome } \\
\text { objective }\end{array}$ & $\begin{array}{l}\text { Participant } \\
\text { (n) }\end{array}$ & status & $\begin{array}{l}\text { Date } \\
\text { complete }\end{array}$ & $\begin{array}{ll}\text { Trial registratic } \\
\text { number }\end{array}$ \\
\hline $\begin{array}{l}\text { Medical } \\
\text { thoracoscopy \& } \\
\text { talc poudrage }\end{array}$ & $\begin{array}{l}\text { Small bore chest } \\
\text { drain \& talc } \\
\text { pleurodesis }\end{array}$ & $\begin{array}{l}\text { Randomised, } \\
\text { non-blinded }\end{array}$ & Multicentre & $\begin{array}{l}\text { Rate of } \\
\text { pleurodesis failure }\end{array}$ & 330 & Completed & $\begin{array}{l}\text { October } \\
2017\end{array}$ & ISRCTN47845793 \\
\hline $\begin{array}{l}\text { Sliver nitrate } \\
\text { eluting catheter }\end{array}$ & Standard IPC & $\begin{array}{l}\text { Randomised, } \\
\text { single blinded }\end{array}$ & Multicentre & Pleurodesis rates & 118 & Completed & $\begin{array}{l}\text { April } \\
2018\end{array}$ & NCT02649894 \\
\hline $\begin{array}{l}\text { IPC \& talc } \\
\text { pleurodesis }\end{array}$ & $\begin{array}{l}\text { Chest drain \& } \\
\text { talc pleurodesis }\end{array}$ & $\begin{array}{l}\text { Randomised, } \\
\text { non-blinded }\end{array}$ & Multicentre & $\begin{array}{l}\text { Health-related } \\
\text { QoL }\end{array}$ & 142 & Recruiting & N/A & ISRCTN15503522 \\
\hline VAT-PD & Standard IPC & $\begin{array}{l}\text { Randomised, } \\
\text { non-blinded }\end{array}$ & Multicentre & Breathlessness & 38 & Recruiting & $\mathrm{N} / \mathrm{A}$ & NCT03412357 \\
\hline $\begin{array}{l}\text { IPC } \pm \text { talc } \\
\text { pleurodesis }\end{array}$ & $\begin{array}{l}\text { VATS } \\
\text { Pleurodesis }\end{array}$ & $\begin{array}{l}\text { Randomised, } \\
\text { non-blinded }\end{array}$ & Multicentre & $\begin{array}{l}\text { Requirement for } \\
\text { ipsilateral pleural } \\
\text { procedure }\end{array}$ & 160 & Recruiting & N/A & $\begin{array}{l}\text { ACTRN12618001013 } \\
57\end{array}$ \\
\hline $\begin{array}{l}\text { IPC + } \\
\text { iodopovidone }\end{array}$ & IPC + placebo & $\begin{array}{l}\text { Randomised, } \\
\text { double } \\
\text { blinded }\end{array}$ & $\begin{array}{l}\text { Single } \\
\text { centre }\end{array}$ & $\begin{array}{l}\text { Time to catheter } \\
\text { removal }\end{array}$ & 72 & Recruiting & $\mathrm{N} / \mathrm{A}$ & NCT03325192 \\
\hline $\begin{array}{l}\text { TUS before \& } \\
\text { post talc } \\
\text { administration. }\end{array}$ & $\begin{array}{l}\text { Talc pleurodesis } \\
\text { with no TUS }\end{array}$ & $\begin{array}{l}\text { Randomised, } \\
\text { non-blinded }\end{array}$ & Multicentre & $\begin{array}{l}\text { Length of hospital } \\
\text { stay }\end{array}$ & 344 & Recruiting & N/A & ISRCTN16441661 \\
\hline $\begin{array}{l}\text { Thoracoscopy } \\
\text { and talc } \\
\text { poudrage and } \\
\text { IPC with } \\
\text { outpatient } \\
\text { management }\end{array}$ & $\begin{array}{l}\text { Thoracoscopy } \\
\text { and poudrage } \\
\text { with admission } \\
\text { for a chest drain }\end{array}$ & $\begin{array}{l}\text { Randomised, } \\
\text { non-blinded }\end{array}$ & Multicentre & $\begin{array}{l}\text { Need for further } \\
\text { pleural } \\
\text { interventions over } \\
3 \text { months post } \\
\text { randomisation }\end{array}$ & 150 & $\begin{array}{l}\text { Due to start } \\
2019 / 2020\end{array}$ & $\mathrm{~N} / \mathrm{A}$ & Awaited \\
\hline
\end{tabular}

An electronic search was made on PubMed on April 1st, 2019 with the Title/Abstract terms "malignant pleural", "randomisation", "prognosis" and "non-expandable", with the filter "last 10 years" activated for completed studies and published protocols. The search identified 406 citations. We used ClinicalTrials.gov to identify current recruiting trials in MPE, identifying 115 trials. We evaluated studies that investigated recent advances in the prognostication or management in MPE and selected the studies which were felt to be most relevant to the field. 
1. The evidence base for the management of a MPE has increased dramatically over the last decade and the guidelines need to be updated to reflect this.

2. Manometry does not currently have a role in routine therapeutic aspirations but may be helpful in identifying patients with non-expandable lung

3. Prognostication for patients with MPE has improved with the introduction of new prognostic scores but the role in routine clinical practice is unclear.

4. Sterile talc is the most effective pleurodesis agent. Previous RCTs comparing slurry to poudrage have been inconclusive due to methodological issues. The TAPPS study should provide additional robust insight to this question.

5. Smaller bore chest drains may not be as effective as larger bore drains in delivering pleurodesis, but this may be due to tube blockage or displacement, rather than the absolute diameter.

6. The option of IPC or chest drain and pleurodesis should be presented as equal treatments in patients with fully expandable lung, with the final decision decided by patient preference.

7. Outpatient talc pleurodesis via an IPC is safe and increases rates of pleurodesis compared to IPC alone.

8. IPCs can be used as a vehicle for other treatments, either to promote pleurodesis or address the underlying disease process and its capacity in this area has yet to be fully recognised.

\section{References}

1. American Thoracic S. Management of malignant pleural effusions. Am J Respir Crit Care Med. 2000;162(5):1987-2001.

2. Roberts ME, Neville E, Berrisford RG, Antunes G, Ali NJ. Management of a malignant pleural effusion: British Thoracic Society Pleural Disease Guideline 2010. Thorax. 2010;65 Suppl 2:ii32-40.

3. Lee YC, Fysh ET. Indwelling pleural catheter: changing the paradigm of malignant effusion management. JThorac Oncol 2011;6(4):655-7.

4. Lentz RJ, Lerner AD, Pannu JK, Merrick CM, Roller L, Walston C, et al. Routine monitoring with pleural manometry during therapeutic large-volume thoracentesis to prevent pleural-pressurerelated complications: a multicentre, single-blind randomised controlled trial. Lancet Respir Med 2019 May;7(5):447-455

5. Feller-Kopman D, Walkey A, Berkowitz D, Ernst A. The relationship of pleural pressure to symptom development during therapeutic thoracentesis. Chest. 2006;129(6):1556-60.

6. Krenke R, Grabczak EM. Pleural manometry and thoracentesis-is the issue resolved? Lancet Respir Med 2019;7(5):374-6.

7. Martin G, Kidd A, Tsim S, Woodward R, Hopkins T, Foster J, et al. S134 Pre-EDIT: a randomised, feasibility trial of elastance-directed intra-pleural catheter or talc pleurodesis (EDIT) in the management of symptomatic malignant pleural effusion without obvious non-expansile lung. Thorax. 2018;73(Suppl 4):A83-A4.

8. Clive AO, Jones HE, Bhatnagar R, Preston NJ, Maskell N. Interventions for the management of malignant pleural effusions: a network meta-analysis. Cochrane Database Syst Rev. 2016(5):Cd010529.

9. Bhatnagar R, Laskawiec-Szkonter M, Piotrowska HE, Kahan BC, Hooper CE, Davies HE, et al. Evaluating the efficacy of thoracoscopy and talc poudrage versus pleurodesis using talc slurry (TAPPS trial): protocol of an open-label randomised controlled trial. BMJ open. 2014;4(11):e007045. 
10. Rahman NM, Pepperell J, Rehal S, Saba T, Tang A, Ali N, et al. Effect of Opioids vs NSAIDs and Larger vs Smaller Chest Tube Size on Pain Control and Pleurodesis Efficacy Among Patients With Malignant Pleural Effusion: The TIME1 Randomized Clinical Trial. JAMA. 2015;314(24):2641-53.

11. Zhu Z, Donnelly E, Dikensoy O, Misra H, Bilaceroglu S, Lane KB, et al. Efficacy of ultrasound in the diagnosis of pleurodesis in rabbits. Chest 2005;128(2):934-9.

12. Corcoran JP, Hallifax RJ, Mercer RM, Yousuf A, Asciak R, Hassan M, et al. Thoracic Ultrasound as an Early Predictor of Pleurodesis Success in Malignant Pleural Effusion. Chest. 2018;154(5):1115-

20.

13. Rintoul RC, Ritchie AJ, Edwards JG, Waller DA, Coonar AS, Bennett M, et al. Efficacy and cost of video-assisted thoracoscopic partial pleurectomy versus talc pleurodesis in patients with malignant pleural mesothelioma (MesoVATS): an open-label, randomised, controlled trial. Lancet. 2014;384(9948):1118-27.

14. Davies HE, Mishra EK, Kahan BC, Wrightson JM, Stanton AE, Guhan A, et al. Effect of an indwelling pleural catheter vs chest tube and talc pleurodesis for relieving dyspnea in patients with malignant pleural effusion: the TIME2 randomized controlled trial. JAMA. 2012;307(22):2383-9. 15. Thomas R, Fysh ET, Smith NA, Lee P, Kwan BC, Yap E, et al. Effect of an indwelling pleural catheter vs talc pleurodesis on hospitalization days in patients with malignant pleural effusion: The AMPLE randomized clinical trial. JAMA 2017;318(19):1903-12.

16. Wahidi MM, Reddy C, Yarmus L, Feller-Kopman D, Musani A, Shepherd RW, et al. Randomized trial of pleural fluid drainage frequency in patients with malignant pleural effusions. The ASAP trial. Am J Respir Crit Care Med. 2017;195(8):1050-7.

17. Muruganandan S, Azzopardi M, Fitzgerald DB, Shrestha R, Kwan BC, Lam DC, et al. Aggressive versus symptom-guided drainage of malignant pleural effusion via indwelling pleural catheters (AMPLE-2): an open-label randomised trial. Lancet Respir Med 2018;6(9):671-80.

18. Bhatnagar R, Keenan EK, Morley AJ, Kahan BC, Stanton AE, Haris M, et al. Outpatient talc administration by indwelling pleural catheter for malignant effusion. New Engl J Med.

2018;378(14):1313-22.

19. Penz ED, Mishra EK, Davies HE, Manns BJ, Miller RF, Rahman NM. Comparing cost of indwelling pleural catheter vs talc pleurodesis for malignant pleural effusion. Chest. 2014;146(4):991-1000.

20. Mishra EK, Clive AO, Wills GH, Davies HE, Stanton AE, Al-Aloul M, et al. Randomised Controlled Trial of Urokinase versus Placebo for Non-draining Malignant Pleural Effusion. Am J Respir Crit Care Med. 20172018 Feb 15;197(4):502-508

21. Clive AO, Kahan BC, Hooper CE, Bhatnagar R, Morley AJ, Zahan-Evans N, et al. Predicting survival in malignant pleural effusion: development and validation of the LENT prognostic score. Thorax. 2014;69(12):1098-104.

22. Psallidas I, Kanellakis NI, Gerry S, Thezenas ML, Charles PD, Samsonova A, et al. Development and validation of response markers to predict survival and pleurodesis success in patients with malignant pleural effusion (PROMISE): a multicohort analysis. Lancet Oncol. 2018;19:930-939.

23. Psallidas I, Piotrowska HE, Yousuf A, Kanellakis NI, Kagithala G, Mohammed S, et al. Efficacy of sonographic and biological pleurodesis indicators of malignant pleural effusion (SIMPLE): protocol of a randomised controlled trial. BMJ Open Respir Res 2017;4(1):e000225.

24. Baas P, Burgers S. Malignant pleural effusions: will PROMISE make its name true? Lancet Oncol 2018;19(7):853-5.

25. Feller-Kopman DJ, Reddy CB, DeCamp MM, Diekemper RL, Gould MK, Henry T, et al. Management of Malignant Pleural Effusions. An Official ATS/STS/STR Clinical Practice Guideline. Am J Respir Crit Care Med 2018;198(7):839-49.

26. Bibby AC, Dorn P, Psallidas I, Porcel JM, Janssen J, Froudarakis M, et al. ERS/EACTS statement on the management of malignant pleural effusions. ERJ. 2018;52(1):1800349. 
27. Bhatnagar R, Zahan-Evans N, Kearney C, Edey AJ, Stadon L, Tremblay A, et al. A novel drugeluting indwelling pleural catheter for the management of malignant effusions. Am J Respir Crit Care Med 2018;197(1):136-8.

28. Astoul P, Lee YCG, Maskell NA, Marquette C-H, Johnson N, Whittaker S, et al. A novel pleural-bladder pump for management of pleural effusion. ERJ 2013;42(Suppl 57):P3081

29. Arber A, Spencer L. 'It's all bad news': the first 3 months following a diagnosis of malignant pleural mesothelioma. Psychooncology. 2013;22(7):1528-33.

30. Girgis S, Lambert S, Waller A, Girgis A. "It sort of hit me like a baseball bat between the eyes": a qualitative study of the psychosocial experiences of mesothelioma patients and carers. Support Care Cancer. 2019;27(2):631-8.

31. Brims F, Gunatilake S, Lawrie I, Marshall L, Fogg C, Qi C, et al. Early specialist palliative care on quality of life for malignant pleural mesothelioma: a randomised controlled trial. Thorax. 2019;74(4):354-61.

32. Muruganandan S, Jeffery E, McIntyre C, Lee YG. Nutrition, exercise, and complementary medicine: potential role in mesothelioma? Curr Pulmonol Rep. 2016;5(1):20-7.

33. Hollen PJ, Gralla RJ, Liepa AM, Symanowski JT, Rusthoven JJ. Adapting the Lung Cancer Symptom Scale (LCSS) to mesothelioma: Using the LCSS-meso conceptual model for validation. Cancer: 2004;101(3):587-95.

34. Lee YG, Wilkosz S. Malignant pleural effusions: fixing the leaky faucet. Am J Respir Crit Care Med $2008 \mathrm{Jul} 1 ; 178(1): 3-5$.

35. Stathopoulos GT, Kalomenidis I. Malignant pleural effusion: tumor-host interactions unleashed. Am J Respir Crit Care Med 2012;186(6):487-92.

36. DeLong P, Carroll RG, Henry AC, Tanaka T, Ahmad S, Leibowitz MS, et al. Regulatory T cells and cytokines in malignant pleural effusions secondary to mesothelioma and carcinoma. Cancer Biol Ther 2005;4(3):342-6.

37. Han H-S, Eom D-W, Kim JH, Kim K-H, Shin H-M, An JY, et al. EGFR mutation status in primary lung adenocarcinomas and corresponding metastatic lesions: discordance in pleural metastases. Clin Lung Cancer 2011;12(6):380-6.

38. Murthy P, Ekeke CN, Russell KL, Butler SC, Wang Y, Luketich JD, et al. Making cold malignant pleural effusions hot: driving novel immunotherapies. Oncoimmunology 2019:1-24.

39. Du N, Li X, Li F, Zhao H, Fan Z, Ma J, et al. Intrapleural combination therapy with bevacizumab and cisplatin for non-small cell lung cancer-mediated malignant pleural effusion. Oncol Rep 2013;29(6):2332-40.

40. Jones DR, Taylor MD, Petroni GR, Shu J, Burks SG, Daniel TM, et al. Phase I trial of intrapleural docetaxel administered through an implantable catheter in subjects with a malignant pleural effusion. J Thorac Oncol 2010;5(1):75-81.

41. Gattinoni L, Powell Jr DJ, Rosenberg SA, Restifo NP. Adoptive immunotherapy for cancer: building on success. Nat Rev Immunol 2006;6(5):383.

42. Sterman DH, Recio A, Haas AR, Vachani A, Katz SI, Gillespie CT, et al. A phase I trial of repeated intrapleural adenoviral-mediated interferon-beta gene transfer for mesothelioma and metastatic pleural effusions. Mol Ther 2010;18(4):852-60.

43. Sterman DH, Recio A, Carroll RG, Gillespie CT, Haas A, Vachani A, et al. A phase I clinical trial of single-dose intrapleural IFN-beta gene transfer for malignant pleural mesothelioma and metastatic pleural effusions: high rate of antitumor immune responses. Clin Cancer Res 2007;13(15 Pt 1):4456-66.

44. Aggarwal C, Haas AR, Metzger S, Aguilar LK, Aguilar-Cordova E, Manzanera AG, et al. Phase I Study of Intrapleural Gene-Mediated Cytotoxic Immunotherapy in Patients with Malignant Pleural Effusion. Mol Ther 2018;26(5):1198-205.

45. Ren S, Terman DS, Bohach G, Silvers A, Hansen C, Colt H, et al. Intrapleural staphylococcal superantigen induces resolution of malignant pleural effusions and a survival benefit in non-small cell lung cancer. Chest 2004;126(5):1529-39. 